\title{
Hot sur de Laura Restrepo: La prevalencia del orden jurídico sobre el humanista hacia el inmigrante ${ }^{1}$
}

\section{Laura Restrepo's Hot sur: The prevalence of legal order over humanist order toward the immigrant}

\author{
Elizabeth Hernández AlvíDrez*
}

Rose no sabría cómo describir aquello, ni cómo explicar la razón de ser de ese espectacular despliegue de poder justiciero y de fuerza coercitiva, esa demostración de la grandeza de los jueces, las autoridades, los fiscales, los celadores, los guardianes, los vecinos honestos y demás ciudadanos de bien, frente a la presunta insignificancia e infamia de los prisioneros. Alguien, más precisamente el Estado americano, se había tomado el trabajo y había invertido millones en construir aquel monstruo con el fin de impresionar y aleccionar.

Laura Restrepo, Hot sur

Resumen:

En la novela Hot Sur de Laura Restrepo seguimos el trayecto del personaje María Paz, inmigrante colombiana, acusada de

* Universidad Pedagógica Nacional-Ajusco.

${ }^{1}$ Este artículo se deriva de la investigación "La pertinencia educativa de la hermenéutica de Giorgio Agamben para la comprensión de la diversidad mediante la narrativa literaria", registrada en el Área de Diversidad e interculturalidad de la Universidad Pedagógica Nacional-Ajusco, 2017-2018. 
asesinar a su esposo, recluida en la cárcel de Manninpox, en las cercanías de Nueva York. En este artículo se realiza una interpretación de esta obra desde la hermenéutica del filósofo italiano Giorgio Agamben. La hipótesis interpretativa que guía el análisis consiste en un problema que expone esta novela: en el contexto de la migración prevalece el orden jurídico sobre el de los afectos humanitarios, aunque este último orden es el que echa a andar la acción de la trama. El procedimiento metodológico que se aplica consiste en observar las signaturas, es decir, la manera en que las concepciones de y hacia los personajes se manifiestan en sus discursos y en sus actitudes, en los que prevalecen los términos jurídicos y de diferenciación, así como de rechazo del otro.

\section{Palabras clave:}

hermenéutica, signaturas, inmigrante, ciudadanía, humanismo.

\section{Abstract:}

In Laura Restrepo's Hot sur we follow the journey of María Paz character, a Colombian immigrant, acussed of murdering her husband and incarcerated in Manninpox prison, near New York. The present article interprets this novel through the hermeneutics of Italian philosopher Giorgio Agamben. The interpretative hypothesis, which guides the analysis, consists in a problem exposed by the novel: within the context of migration, legal order has prevalence over humanitarian affections, even though this last one sets the plot in motion. The methodological procedure applied here, consists on observing signatures, that is, how conceptions of and toward characters are manifested in their speech and attitudes, in which legal and differentiative terms, as well as terms for rejecting the Other, have prevalence.

Key Words:

Hermeneutics, Signatures, Immigrant, Citizenship, Humanism. 


\section{Introducción}

Los recientes acontecimientos en relación con los migrantes en Estados Unidos nos muestran la perspectiva de este hecho por parte de los ciudadanos en ese país. La misma actitud de estos últimos también está presente, en cierta medida, en el contexto latinoamericano, lo que nos conduce a reflexionar sobre este problema. Un ejemplo de ello son los comentarios de lectores, que diversos medios de comunicación muestran, acerca de las personas que migraron hacia los Estados Unidos con el fin, principalmente, de mejorar sus condiciones de vida, quienes recientemente han sido sometidas a la deportación con consecuencias que han llegado a extremos de suicidio o de muerte espantosa en el caso de quienes persisten en el intento de migrar en condiciones inhumanas. No deja de llamar la atención la respuesta que desde la comprensión práctica dan las personas distanciadas de la experiencia propia de esta situación. En efecto, respecto a este hecho se impone la idea de la condición ilegal de los migrantes como justificación y aceptación del trato que se les da.

La hermenéutica de Paul Ricoeur nos enseña que vivimos en un orden fundado en conceptos, símbolos y caracteres temporales que, si bien nos sirven para organizar el día a día, pueden llegar a convertirse en metáforas muertas que impiden un mejor modo de vida. Ricoeur ve en la comprensión de la historicidad humana una vía para tomar distancia de concepciones que constituyen un polo negativo de la ideología y, en la narrativa literaria, una vía para explorar críticamente dicha historicidad. En este artículo abordamos el distanciamiento del orden de vida desde la perspectiva hermenéutica del filósofo italiano Giorgio Agamben, quien nos ofrece una mirada actual del problema humano de la migración. Para comprender lo que genera la opinión pública frente al migrante partimos del término básico foucaultiano de "dispositivo" que Giorgio Agamben toma y desarrolla en aplicaciones actuales:

a. El dispositivo es un conjunto heterogéneo, que incluye virtualmente cualquier cosa, lingüístico y no lingüístico al mis- 
mo nivel: discursos, instituciones, edificios, leyes, medidas policiales, proposiciones filosóficas, etc. El dispositivo es en sí mismo la red que se establece entre estos elementos.

b. El dispositivo siempre tiene una función estratégica concreta y siempre se inscribe en una relación de poder.

c. Como tal, resulta del cruce de relaciones de poder y de relaciones de saber. (Agamben, ¿Qué es un dispositivo? 11)

Agamben considera que: "Probablemente no sería errado definir la fase extrema del desarrollo capitalista que estamos viviendo como una gigantesca acumulación y proliferación de dispositivos" (¿Qué es un dispositivo? 25). Una preocupación filosófica del autor consiste en que el estado de excepción se ha vuelto la regla en la crisis del Estado-nación moderno que enfrenta con violencia la globalización, en la que las necesidades que generan las migraciones están rompiendo los esquemas territoriales. Por eso le interesa realizar la genealogía del establecimiento del orden jurídico que sustenta la política moderna. Desde esta perspectiva y siguiendo a Ricoeur, podemos advertir que si bien el lenguaje nos constituye como sujetos, y en ese sentido nos sujeta a conceptos, símbolos e historicidades, también mediante el lenguaje podemos hacer la crítica de las ideologías. Por ello, nos resulta aplicable en los estudios culturales, específicamente de la diversidad ${ }^{2}$, el método de interpretación que propone Agamben que es el del análisis de las signaturas:

La teoría de las signaturas (de los enunciados) interviene, entonces, para rectificar la idea abstracta y falaz de que existen signos por así decirlo puros y no signados, de que el signans significa el signatum de modo neutral, unívoco y de una vez por todas. El signo significa porque lleva una signatura, pero ésta predetermina necesariamente su interpretación y distri-

\footnotetext{
${ }^{2}$ Con este propósito en la investigación en curso de la cual deriva este artículo, se tiene la intención de incorporar el enfoque metodológico de Terry Eagleton en su reciente libro Cómo leer literatura, Paidós, 2017.
} 
buye su uso y su eficacia según reglas, prácticas y preceptos que hay que reconocer. La arqueología es, en este sentido, la ciencia de las signaturas. (Agamben, Signatura 86)

Podemos entonces concebir las signaturas como aquellas expresiones lingüísticas que tienen una carga connotativa tal que sostienen la validez de un determinado dispositivo y que pueden llegar a constituirse en performativas, que inciden en la posición de las personas en referencia a un orden establecido. Específicamente, este estudio se dirige al migrante que vive en estado de excepción dentro de una cárcel, fuera de ella en la clandestinidad o en el centro de migrantes en tránsito, lugares todos ellos donde se dispone de la vida como ordenamiento de la ley. Una manera coloquial de definir las signaturas es: lo que se parece a mí es bueno para mí y, al contrario, lo que es diferente a mí es sospechoso y por lo tanto objeto de rechazo en diferentes intensidades de violencia.

Agamben distingue los estudios semiológicos que no consideran el poder discursivo que está detrás del texto de la hermenéutica que busca interpretar las signaturas que marcan los enunciados textuales mediante indicios, como los que interpreta el detective que busca resolver las causas y los agentes del crimen. El autor sugiere la profanación como manera "de liberar lo que ha sido capturado y separado a través de los dispositivos para restituirlo a un posible uso común" (¿Qué es un dispositivo? 27). La narración literaria es una actividad que posibilita la mirada sobre la profanación de lo establecido por los dispositivos. Por ello se presta para mostrar y comprender las signaturas que evidencian dispositivos en actividad: es el caso de la novela Hot sur de Laura Restrepo, en la que nos detendremos a continuación.

\section{Signaturas hacia el inmigrante en Hot sur}

La migración es uno de los temas que aborda la narrativa de Laura Restrepo, tanto interna en un país, por motivos de desplazamientos debido a guerrillas o al narcotráfico, como externa, a causa de 
la explotación de la tierra por agentes capitalistas extranjeros. Por ejemplo, en su novela La multitud errante, el tema de la migración está relatado desde la perspectiva de los desplazados. La historia se sitúa en el contexto colombiano en el que grandes grupos de población se ven obligados a abandonar sus comunidades a causa de las acciones emprendidas tanto por las fuerzas militares gubernamentales como por la guerrilla. Son personajes en éxodo, errantes, caminantes, como los define la narradora. En otra novela, Leopardo al sol, se da cuenta del paso de las formas de vida y trabajo tradicionales a las del contrabando, el narcotráfico y la delincuencia organizada, como una consecuencia de la migración del campo a la ciudad. La historia revela la transformación social y cultural, que se deriva de este cambio de actividades de sustento, como una transición que marca el destino de Colombia. Por su parte, en La isla de la pasión, la profesión periodística de la autora sirve para que en el contexto mexicano, en donde estuvo parte de su exilio, se preocupe por indagar y novelar una historia real que aconteció a finales de la época porfiriana y los principios de la revolución mexicana. Se podría establecer una relación entre su interés por investigar y su interés por novelar los hechos de una vivencia tan extrema de migración y de alejamiento de la vida cotidiana dentro de un país, como la que vivieron Ramón Arnaud y su esposa Alicia Rovira, cuando él fue nombrado gobernador de la isla de Clipperton, alejada más de 900 kilómetros de México: una experiencia que transformó radicalmente la concepción de vida de los participantes. Restrepo hace en esta novela énfasis en las consecuencias que para la condición humana significan la migración y el aislamiento. En esta narración, la autora interpreta la vida de los Arnaud en la isla como un movimiento vital de angustia, por considerar Ramón que fue un destierro en castigo a su mal comportamiento como militar del ejército mexicano. De esta angustia, la historia pasa al entusiasmo de dar vida y orden a un pequeño reinado, y termina con la locura y el caos de la descomposición humana en condiciones de aislamiento total.

Una pregunta a la que quizás intentan dar respuesta las novelas de Laura Restrepo es la siguiente: ¿Cómo relatar estas formas de la migración forzada cuando quien narra está fuera del contexto no 
solo en relación con el espacio, sino también socioculturalmente? En Hot sur encontramos una respuesta a esta pregunta mediante una estructura donde se conocen diversas perspectivas a través de las voces de los protagonistas.

En la novela Hot sur, que se analiza en este artículo, la migración hacia los Estados Unidos es la circunstancia específica narrada. La perspectiva interpretativa que consideramos puede llevarnos a comprender el problema que saca a la luz esta novela: la búsqueda de las signaturas que ubican al inmigrante latinoamericano en lo que Giorgio Agamben llama el estado de excepción, al ser considerado su estatus como separado de la esfera política, despojado de una ciudadanía de primera o hasta de cualquier ciudadanía, por lo cual se autoriza al Estado a disponer de su vida.

La trama, ubicada en la ciudad de Nueva York, gira alrededor del esclarecimiento de un crimen y la ayuda a María Paz, acusada de asesinar a Greg, su esposo, y puesta en prisión aunque es inocente. La novela está conformada por varios géneros textuales, como la entrevista que la narradora - quien participa como personaje dentro de la diégesis y con ello crea una figuración de verosimilitud- hace a Ian Rose para escribir la novela sobre el tema de la inmigrante colombiana María Paz. En la vida de esta se vieron involucrados Cleve Rose, el profesor del taller de escritura creativa en el reclusorio femenino de Maninnpox, y después el mismo Ian Rose tras la muerte de su hijo Cleve. Ian es quien le proporciona a la narradora la perspectiva completa de la historia, pues tiene en su posesión tanto el cuaderno donde su hijo relataba su relación con María Paz, como los escritos autobiográficos que esta redactó con la intención de que fueran publicados como novela. Los acontecimientos relatados en los documentos llevan a Ian a buscar a María Paz, con el fin de conocer los hechos acerca de la muerte de su hijo y lograr el castigo del culpable. Sin embargo, Ian se involucra en la causa justa de María hasta el final liberador.

Los géneros textuales utilizados en Hot sur son: la entrevista de la narradora a Ian Rose, el diario de Cleve Rose, los escritos autobiográficos de María Paz — donde relata su relación con los hermanos de procedencia eslovaca Greg y Sleepy Joe-, así como 
las entrevistas que realiza Ian a otros personajes involucrados con María Paz, como el abogado Pro Bono y Mandra X. En este trabajo nos detendremos en el análisis de los discursos derivados de tales géneros, así como los que se realizan sobre estos personajes. Estos géneros discursivos crean una polifonía en la que los personajes se dan a conocer por sus propias voces, mediante las cuales podemos analizar las signaturas que los caracterizan. Así, Cleve se expresa en el lenguaje de un escritor que ha desarrollado un pensamiento crítico acerca del orden de vida que se impone en los Estados Unidos y las desigualdades que este genera; por este motivo se propone trabajar como profesor de escritura creativa en la cárcel para mujeres de Manninpox. Por su parte, Ian habla como lo hace un profesionista económicamente bien ubicado que se considera un estadounidense de mentalidad abierta. Pro Bono es un abogado que ha acumulado prestigio y dinero y que, por ello, en su vejez está en disposición de ayudar a los desfavorecidos, entre quienes elige a los latinoamericanos. Mandra X se ha formado profesionalmente en la rama jurídica de derechos humanos dentro de la cárcel y elige también aplicar sus conocimientos en la defensa de las reclusas latinoamericanas. Estos personajes actúan como coadyuvantes en el desarrollo de la trama liberadora de María Paz. Los discursos de los hermanos Greg y Sleepy Joe son dados a conocer indirectamente mediante la percepción y la experiencia que de ellos tiene la propia María Paz o por medio de personajes como Wendy Mellons que es entrevistada durante las pesquisas para encontrar a Sleepy Joe. Estos hermanos son personajes que impiden la meta migratoria de María Paz.

El tono de la novela es irónico, lo que permite observar que el lenguaje que usan los personajes, puede interpretarse como revelación de las signaturas que subyacen en sus discursos. El estado de ánimo es por lo tanto cuestionador. La cadencia narrativa oscila entre la violencia, el amor, la comprensión y la reflexión. El género es indagatorio, una pesquisa para obtener la verdad y una aventura para liberar a la perseguida, a quien se ayuda no a entrar en el país, sino irónicamente a escapar del "sueño americano" que se convierte en pesadilla. La gramática y la sintaxis ordenan las secuencias de 
modo acorde con el registro cultural de cada personaje. La textura es alternante en función de los contextos culturales, socioeconómicos y profesionales de los personajes. El ritmo narrativo es ágil, pues la acción se centra tanto en la búsqueda de la verdad acerca de los hechos que llevan a la narradora-personaje a escribir el libro, como en la empresa de salvación de la migrante inocente pero en peligro por su propia condición jurídica en el país. La ambigüedad se da mediante el uso de la ironía y la construcción de imágenes que requieren mayor atención.

La hermenéutica de Agamben nos guía para interpretar en la novela una isotopía narrativa que proponemos como hipótesis. En este propósito, la reflexión se centra en el análisis de las concepciones del migrante, que cada personaje expresa lingüísticamente desde su perspectiva ideológica socio-cultural mediante la detección de las signaturas que definen a este último y que lo hacen objeto de acción por parte del Estado y ante el ciudadano estadounidense. Siguiendo a Agamben, la hipótesis interpretativa es que un problema que expone esta novela es que en el contexto de la migración prevalece el reconocimiento del otro como semejante desde un orden jurídico y no desde el orden humano. Sin embargo, este último orden es el que echa a andar la acción. María Paz, como personaje que centra la constitución de la trama, tiene coadyuvantes en la resolución de su problema. Lo interesante es conocer los motivos que intervienen para brindar esta ayuda, a pesar de la permanencia en sus coadyuvantes de las signaturas que marcan como diferente y riesgoso al inmigrante y, por lo tanto, a María Paz.

Un rasgo que une a algunos personajes coadyuvantes es la atracción erótica hacia María Paz. En el joven profesor Cleve Rose podemos observar una signatura respecto a la mujer latinoamericana que la presenta como objeto del deseo creado en la niñez cuando vivió con su padre y su madre en Colombia. El octogenario abogado Pro Bono que participa de manera filantrópica en su defensa, confiesa a Ian Rose su atracción erótica hacia María Paz, aunque no haya intentado tener relación sexual con ella. El mismo Ian Rose, quien entra en contacto con María Paz con la finalidad de atrapar al asesino de su hijo, actúa también en su beneficio en respuesta a 
una inclinación erótico-afectiva cuando convive con ella en el trayecto de su liberación. Un personaje coadyuvante de María Paz que tiene también la característica de inclinación hacia la mujer latinoamericana, es Mandra X, una presidiaria de Manninpox. Mandra X es alemana y fue recluida por el asesinato de sus hijos trillizos que padecían malformaciones y trastornos de nacimiento. Cuando fue diagnosticada con cáncer, dio muerte a sus hijos por motivos que consideró humanitarios, pues sabía que nadie se haría cargo de ellos cuando faltara. Sin embargo, ella no murió, y ya como prisionera en cadena perpetua se convirtió en especialista en derechos humanos, líder de un grupo de poder en la cárcel y fuera de ella, y defensora de las presidiarias latinoamericanas, con quienes se identificaba porque había vivido en Latinoamérica y sabía hablar español.

Mandra X es uno de los personajes que induce a una interpretación más profunda desde el punto de vista de las signaturas, pues su historia evoca otro estado de excepción: el que se ejerció en la Alemania nazi. El indicio que se muestra en la diégesis es la alusión a la eugenesia, que ella comprende que prevalece actualmente - como en el caso de gran parte de las presidiarias - al saber que vivimos en una sociedad en que es difícil hacerse cargo de vidas que no cuadran en el orden de la comunidad, como las de sus hijos. El caso de este personaje muestra un contraste que se presenta en la novela entre la signatura de la limpieza y el cuidado del cuerpo como orden aceptable, y la de la suciedad y el uso del cuerpo como transgresión de las normas de cuidado.

Los hermanos de origen eslovaco Greg y Sleepy Joe figuran en la narración como motivadores de la caída en desgracia de María Paz. El primero, viudo cincuentón, es el esposo por conveniencia de María Paz en su búsqueda de estatus legal en Estados Unidos; el segundo es el joven cuñado de María Paz, con quien establece una relación sexual de fuerte atracción. Greg es un policía retirado que se dedica al tráfico de armas en colusión con otros miembros del cuerpo policíaco. Su hermano menor, Sleepy Joe, se presenta en la trama como un psicópata asesino.

¿Cuáles son los paralelismos, los contrastes y las conexiones que pueden establecerse entre estos personajes? En principio, to- 
dos están relacionados con los latinoamericanos y de alguna manera todos son descendientes de inmigrantes. Aunque en el caso de los hermanos eslovacos esta relación tiene características especiales, pues en su infancia se relacionaron con la comunidad hispana del estado de Colorado, en el intento de ser admitidos en la hermandad de los Penitente Brothers del Sangre de Cristo, treinta años antes de la acción principal de la novela. El intento de Sleepy Joe de ingresar a la hermandad mediante una ceremonia violenta de rito de paso, con la cual no logra su objetivo, muestra un inicio que pone ante los ojos del lector la oscuridad de este personaje que treinta años después será uno de los causantes de las desgracias que sufre María Paz. Nunca se da a conocer en la historia por qué la hermandad no acepta a los hermanos. Una posible interpretación podría ser que la violencia fanática de Sleepy Joe sobrepasa la admitida por la hermandad. Otra explicación puede ser que, al tratarse de una hermandad cuyos miembros son de origen hispano, el inmigrante eslovaco no es aceptado; esto explicaría la animadversión de Sleepy Joe hacia los latinoamericanos. Por su parte, Greg se convertirá en policía en Nueva York y se involucrará en el tráfico de armas dentro de esta corporación, lo cual fue la verdadera causa de su asesinato.

Los contrastes se ubican en el plano de lo que podríamos llamar una gradación en el estatus de ciudadanía: primero están los blancos, anglosajones y protestantes, entre los cuales se encuentran Ian y Cleve Rose y Pro Bono; después los europeos de otras procedencias y otras religiones, principalmente la católica, como Greg, Sleepy Joe y Mandra X; habría que considerar también a los indígenas estadounidenses, que paradójicamente comparten en gran medida el estatus de los migrantes, desde la perspectiva de que Estados Unidos se concibe como nación fundada bajo los principios del Estado moderno, por lo cual se parte de la idea de "borrón y cuenta nueva" respecto a los habitantes originarios de ese territorio; por último están los asiáticos, africanos y latinoamericanos, como María Paz, la gran mayoría de las reclusas de Manninpox y los inmigrantes "libres" que viven en zonas de la ciudad donde se concentran los migrantes, los barrios multirraciales y conflictivos. De acuerdo con Agamben estos últimos son campos donde se ejerce el estado de excepción. 
Dentro del marco del manejo jurídico se establece un contraste entre Pro Bono y Mandra X. Ambos se sitúan en el lado de la defensa de los marginados, pero el abogado lo hace sin salir del límite de las instituciones, mientras que Mandra X se desempeña en la subversión de estos marcos:

Mandra X les proponía algo semejante a un pacto de esclavos para que no dejaran de ser humanas en condiciones inhumanas de vida. Y además eran todas latinas, ése era el factor común. Siendo ella misma aria, se había convertido en cabeza del clan latino. . . . En el fondo, lo que Mandra X divulga es que en la cárcel se puede llevar una vida plenamente humana, si se lucha por eso con suficiente empecinamiento. (296-97)

Mientras que Mandra X interpela a la sociedad mediante un uso violento del cuerpo, Pro Bono reivindica la validez de su cuerpo malformado: "Él iba a demostrar con su propia vida que un jorobado podía ser un buen tipo, compasivo y solidario, útil a la sociedad" (131). Mandra X practica la automutilación, el tatuaje, la suciedad. Contrariamente, Pro Bono exagera la limpieza y el lujo en sí mismo y en lo que lo rodea. Ambos establecen la soberanía de su cuerpo de manera contrastante. Desde el punto de vista operativo, Mandra $\mathrm{X}$ y Pro Bono mantienen una relación en la defensa de las reclusas. Pero Mandra X se ha dado cuenta de que los rituales establecen la solidez de la subversión hacia los dispositivos del poder. Esto lo comprendió muy bien Pro Bono, quien dice:

Las seguidoras del Noli me tangere se guiaban por un credo elemental de supervivencia y respeto. Hasta ahí, lo concreto. Pero Mandra X era zorra vieja y sabía que el asunto no le funcionaba si no le ponía su misterio y su culto, su ceremonia y su retórica. En la cárcel, como también fuera de ella, pero sobre todo en la cárcel, la forma era indispensable para que hubiera contenido. Sin actitud no había significado, y sin ritualidad no había compromiso. (295) 
Estas palabras dan cuenta de que las signaturas se revierten para desactivar las relaciones de poder. En efecto, Mandra X crea un orden en que las signaturas permiten la identificación de las reclusas que ingresan al grupo de las Nolis. Mandra X profana el dispositivo carcelario, pues con las mismas herramientas de los derechos humanos transgrede el orden del Estado moderno para dar lugar a otra forma de humanismo.

Una acción en la que Pro Bono llega a transgredir los marcos jurídicos se presenta cuando se da cuenta de que el caso de María Paz está perdido ante las instancias de juicio, pues en ellas se da primacía a la salvaguarda del honor de la corporación policíaca, dentro de la cual se practicaba el tráfico de armas, motivo por el que, como ya se mencionó, Greg, esposo de María Paz, fue asesinado. El honor corporativo se antepone a la justicia para el inmigrante. Se observa otro ejemplo de que las signaturas con las que se percibe a este último facilitan la disposición de su vida. En este caso, Pro Bono advierte la imposibilidad de ganar el juicio que libere a María Paz por la manera en que es presentada por la prensa ante la opinión pública, entre la que se encuentra su jurado. Pro Bono instruye a María Paz sobre la mejor manera de impresionar positivamente a los miembros del jurado mediante la apariencia, es decir, las signaturas, en una idea de que el hábito hace al monje:

Pro Bono no sólo la prepara para el juicio, sino que además le cumple la promesa de acompañarla personalmente a comprar ropa buena, para que se presente como una princesa ante el juez. Le asegura que el aspecto es decisivo en esos casos porque los jueces no escuchan razones, están hartos de escuchar razones y toman su decisión más bien a partir de un golpe de ojo, o inclusive de olfato. Pro Bono la lleva a Sacks Fifth Avenue. María Paz protesta, no está nada convencida, se queja de que en esa tienda todo es carísimo y poco juvenil. Muy señorero según dice. Así tienes que verte, trata de explicarle Pro Bono, como una señora, una señora bonita y elegante. Y sobre todo una señora inocente; los jueces tienden a creer que las señoras inocentes son las que visten ropa costosa. (334) 
En esta parte, Pro Bono da cuenta de las signaturas que caracterizan a la mujer estadounidense aceptable. Más adelante define las signaturas que, por el contrario, presentan a la mujer latinoamericana como negativa ante los ojos estadounidenses.

Desde el punto de vista del abogado Pro Bono, en el juicio la apariencia es determinante para quienes emiten el veredicto, por ello: "Le aconseja que no se maquille demasiado, que no se pinte de rojo los labios, ni las uñas, nada. Discreción ante todo, le dice, no basta con ser inocente, también hay que parecerlo" (335). En otras palabras parecerse al ciudadano ejemplar estadounidense es el camino más seguro, mientras que el cabello largo y el maquillaje excesivo son expresiones de las signaturas que marcan a la inmigrante latina. Sin embargo, los dispositivos resultan tener una mayor fuerza para mantener las signaturas vigentes que desfavorecen al inmigrante, como lo muestra el despliegue mediático que el mismo Pro Bono reconoce y que lo conduce a desanimar a María Paz en su búsqueda de justicia, con lo cual la convierte en prófuga:

En uno de los varios metros que toma ese día, alguien a su lado lee el Daily News, y ella alcanza a ver las fotos y a leer los titulares. Gran despliegue. A la derecha de una de las páginas centrales, Greg muy joven, rubio, apuesto, con su uniforme de Policía. A la izquierda, Greg vuelto mierda, tirado en una esquina en un gran charco de sangre. Más abajo otra foto de Greg, esta vez con Hero: Conmovedora. Y hay una foto más, oscura y pequeñita: de la propia María Paz. La que le han tomado en Manninpox, desmelenada, con pinta de leona en celo, con todo y ficha de presidiaria sobre el pecho. Basta con un vistazo general para tener claro el mensaje: Colombiana Perversa vs. Good Cop Americano. Pro Bono siempre le ha dicho que los jurados son muy susceptibles a los vaivenes de la opinión pública, y este despliegue publicitario debe tenerlos con el espíritu patriótico exacerbado. A María Paz no le queda difícil atar cabos, y cree intuir por qué su abogado ha sabido de antemano que el veredicto va a ser adverso. Debió alarmarse con lo que vio en los diarios, piensa, y habrá opta- 
do por darme la voz de aviso. A lo mejor fue así. O a lo mejor no, pero al menos ella ya tiene una hipótesis. (395)

El abogado Pro Bono se sitúa también del lado de los humanistas, aunque se mantiene dentro del orden legal, lo cual manifiesta cuando comenta con Ian Rose la mentalidad de quien construyó la cárcel de mujeres de Manninpox:

-Y qué le extraña-dijo Pro Bono, después de leer el libro así por encima-, con esta mentalidad se construyó la América de entonces, y en esta misma mentalidad se apoya la América de hoy.

- Y a usted, ¿no le repugna?_-le preguntó Rose.

— ¿A mí? Sí. Por eso soy defensor, y no fiscal. (302)

Las conexiones entre los cuatro coadyuvantes se realizan mediante la defensa del caso de María Paz. De esta manera Ian y Cleve Rose se relacionan, aunque sea después de la muerte del segundo, por medio del amor padre e hijo, que se constituye como la asunción de la deuda. Ian percibe la estrecha relación entre Cleve y María Paz, lo cual le permite triangular el afecto y así llegar al hijo, de quien por mucho tiempo estuvo alejado en vida, tanto física como afectivamente.

En el diario de Cleve, Ian lee expresiones que revelan claramente las signaturas que les subyacen, como la siguiente:

Paz se me ha convertido en una criatura perturbadora con dos cabezas, una especie de monstruo bicéfalo que me urge descifrar, para tratar de entender la maraña de sentimientos que despierta en mí. La Paz de la primera cabeza viene de un mundo lejano pero que alguna vez allá en Colombia, me abrió sus puertas, alguien a quien yo siento parecido a mí, o igual, o incluso mejor. . . . En el caso de la segunda cabeza es más complicado porque está enraizado en viejos miedos y en prejuicios generalizados de los cuales no puedo decir con honestidad que yo esté del todo exento. (169-170) 
Como estadounidense que se considera liberal, Ian reflexiona y avanza en su concepción del migrante a través de las ideas que su hijo dejó plasmadas en su diario, aunque no llega a liberarse del todo de los prejuicios, como también lo confiesa su hijo.

¿Y cuál es la mirada que sobre sí misma como inmigrante muestra María Paz? La caracterización de María Paz corresponde a una persona con cierta ingenuidad, pero a la vez con capacidad de percepción de las condiciones de la realidad en la que se mueve. María Paz se da a conocer a través de los escritos en donde narra su historia como inmigrante. La textura sonora de los escritos de María Paz es coloquial y saturada de clichés televisivos, fílmicos y de literatura cursi, teatral e irónica. Su modelo de mujer estadounidense es el personaje Holly Golightly, pero no el de la novela de Truman Capote, sino el que encarnó la actriz Audrey Hepburn en la película Desayuno en Tiffany's, que Cleve Rose considera como una interpretación cursi que devalúa la fuerza crítica del correspondiente personaje de la novela. En este caso, se hace uso de la parodia para evidenciar la concepción que llega a tener el inmigrante sobre la transformación de su vida en ese país, al que insiste en llamar América y no Estados Unidos, tomando el todo por la parte: "Ya le digo, míster Rose, América no está en ningún lado. América sólo está en los sueños de los que soñamos con América. Eso lo sé ahora, pero me tomó años descubrirlo" (49).

El matrimonio de María Paz con Greg surge de su interés por obtener la ciudadanía como lo declara en las siguientes expresiones:

Póngase usted a pensar, míster Rose, lo que para una muchacha latina y pobre significa estar por una vez en la vida, ya no del lado de las minorías violentas y los superpredators, sino del lado de la ley y el orden y de los CSI special victims unit. . . Para mí, Greg sí significaba el acceso por la puerta grande. Por fin iba yo a ser cien por cien americana. ¿Sabe lo que eso significa en materia de papeles?". (197-201)

Sin embargo, la condición de migrante y de reclusa son factores de tipo jurídico que condicionan su estatus humano. En la cárcel, 
María Paz aprendió conceptos que le permiten autodefinirse desde la visión jurídica de su realidad, gracias a su integración en el grupo de Mandra X: "Ahora que soy una Noli, sé el significado de palabras como choque, soberanía, libertad, rebeldía, derechos, resistencia" (185). De esta manera, el trayecto de María Paz la lleva a una ubicación que corresponde a una concepción de la realidad distinta a la que conducía sus acciones al llegar a Estados Unidos.

Como reclusa, al principio María Paz es vista de esta manera por las demás presas: "Pero María Paz estaba en una tercera categoría, la de las condenadas por su propia cabeza, las que no cometieron delito pero de todos modos se sienten culpables. Estaba jodida desde antes de empezar, porque la hundía el pequeño fiscal que llevaba dentro, un detractor implacable que no la dejaba dar brinco" (308). Esta vez, María Paz se ubica desde las signaturas del plano jurídico. El personaje muestra una mirada sobre el inmigrante que proyecta las signaturas que lo constituyen como ilegal ante los ciudadanos. Así, María Paz trata de asimilarse a lo que ella considera el modelo que la convierte en aceptable en el medio estadounidense.

\section{Reflexiones finales}

En este trabajo nos hemos limitado a abordar una perspectiva interpretativa: la de las signaturas en la novela Hot sur, que tiene una temática compleja: la condición del migrante en Estados Unidos. Este artículo ha tenido la pretensión de aplicar el método de las signaturas en el análisis literario, como un abordaje pertinente para la comprensión de la diversidad, en este caso del sujeto de la migración en un contexto específico. Hot sur y otras novelas de Restrepo constituyen una exploración literaria del tema de la migración y de la manera en que el Estado moderno ha llegado a convertir en permanente el estado de excepción al despojar a muchas personas del estatus de ciudadanía.

Para concluir este acercamiento al estudio de las signaturas que prevalecen en los dispositivos que constituyen al sujeto migrante se plantean los inicios de respuesta a dos preguntas. Primera, ¿de qué 
condición histórica concreta es producto esta novela? De acuerdo con Agamben, la crisis humana del Estado moderno se evidencia actualmente en la idea de que la ciudadanía y por lo tanto los derechos humanos están ligados al nacimiento dentro de determinado Estado y a la sangre, es decir a la pertenencia a una ascendencia específica. Es decir, se tienen derechos humanos solo si se es ciudadano de un Estado-nación, pero la ciudadanía está condicionada por las signaturas; así el inmigrante es tratado como quien sale del límite del derecho humano. De esta manera, el concepto jurídico de ciudadanía funciona como un dispositivo y las signaturas operan como naturalización de acciones hacia el Otro, el considerado extraño o extranjero. Desde la perspectiva histórica latinoamericana, la novela Hot sur revela el destino que tiene el inmigrante indocumentado en los Estados Unidos, quien ingresa al país en busca de mejores condiciones de vida que se le imposibilitan en su país de origen por causas económicas, políticas y sociales. Como el personaje María Paz, el indocumentado queda excluido del orden jurídico y en consecuencia de la prevalencia de este orden. El migrante experimenta la falta de afectividad humanista en su entorno migratorio. A la vez, debe tener siempre en cuenta el orden legal para eludirlo o burlarlo, lo cual también introduce obstáculos para mantenerse con tranquilidad en la vida cotidiana. Segunda pregunta: ¿qué logros tiene la narración de esta obra? El seguimiento del trayecto del héroe en esta novela - María Paz- favorece el entendimiento de la representación de la condición humana afectada en el contexto de la migración en Estados Unidos en el tiempo presente. Asimismo, nos permite comprender la fuerza performativa de las signaturas, fuerza que se concreta no solo en actitudes frente al migrante sino en acciones de disposición de su vida.

De este modo observamos, en el análisis de la novela, la concepción que los personajes tienen de María Paz como el otro a quien hay que defender o perseguir, siempre con la idea de su estatus de extraña dentro del orden jurídico, por las signaturas que la caracterizan en la mentalidad de quienes entran en contacto con ella. Un buen ejemplo es el caso de Cleve Rose, el joven escritor enamorado de María Paz. Su estado emocional es aquel que 
por excelencia favorece el orden humanista, pero llama la atención que no deja de admitir que alberga prejuicios enraizados en torno al origen latinoamericano de María. Así mismo sucede con la autoconcepción de María Paz, quien se esfuerza por encajar en el modelo óptimo del ciudadano estadounidense, aunque lo haga de manera ingenua siguiendo el paradigma cursi del personaje Holly Goligthly. La novela es relevante porque presenta una situación histórica en la que podemos estudiar esta afectación como algo que no debería presentarse en la sociedad humana.

\section{Bibliografía}

Agamben, Giorgio. Estado de excepción. Adriana Hidalgo, 2004.

- - -. ¿Qué es un dispositivo? seguido de El amigo y de La iglesia y el Reino. Anagrama, 2015.

- - -. Signatura rerum. Sobre el método. Anagrama, 2010.

Eagleton, Terry. Cómo leer literatura. Paidós, 2017.

Restrepo, Laura. Hot Sur. Planeta, 2012.

- - - La isla de la pasión. Punto de lectura, 2007.

- - . La multitud errante. Seix Barral, 2001.

- -. Leopardo al sol. Alfaguara, 2005.

Ricoeur, Paul. Tiempo y narración I: Configuración del tiempo en el relato histórico. Siglo XXI, 1995. 